\title{
Veredas
}

Revista de Estudos Linguísticos

https://periodicos.ufff.br/index.php/veredas/index

\section{Objeto Digital de Ensino-Aprendizagem: um olhar para os multiletramentos e para possibilidades de protagonismo dos alunos ${ }^{1}$}

\section{Digital Teaching and Learning Object: a look into the multiliteracies and the possibilities of students' protagonism}

\author{
Letícia Schach $^{2}$, Greice da Silva Castela ${ }^{3}$ \\ Colégio Evangélico Martin Luther, Brasil; Universidade Estadual do Oeste do Paraná, Brasil
}

Recebido em: 07/11/2019

Aceito em: $23 / 06 / 2020$

\begin{abstract}
RESUMO
Neste artigo, analisamos um Objeto Digital de Ensino-Aprendizagem (ODEA) construído, por meio do software PowerPoint, em um curso de formação continuada para professores de língua portuguesa. Objetivamos verificar a presença de elementos que promovam os letramentos visual e digital. O embasamento teórico está pautado em autores como Lemke (2010), Rojo (2009, 2013, 2017) e Xavier $(2004,2006,2009)$. A pesquisa está fundamentada nos parâmetros da Linguística Aplicada, dentro de uma abordagem qualitativa, com análise documental de um dos ODEAs elaborados na formação continuada ofertada. Como resultado do processo de investigação, verificamos que o ODEA elaborado contempla multiletramentos a partir da presença de elementos multimodais e hipertextuais e pode fomentar o protagonismo dos alunos.

PALAVRAS-CHAVE:
\end{abstract}

Multiletramentos. Multimodalidade. Objetos Digitais de Ensino-Aprendizagem. Formação Docente Continuada. PowerPoint.

\begin{abstract}
In this article we analyze a Digital Teaching and Learning Object (DTLO) created using PowerPoint software in a continuing education course for Portuguese language teachers. We aim to verify the presence of elements that promote visual and digital literacy. The theoretical basis is supported by authors such as Lemke (2010), Rojo $(2009,2013,2017)$ and Xavier $(2004,2006,2009)$. As a result of the research process, we found that the elaborated DTLO contemplates the multiliteracies based on the presence of multimodal and hypertextual elements and can foster the protagonism of the students.

KEYWORDS:

Multiliteracies. Multimodality. Digital Teaching and Learning Objects. Continuing Teaching Formation. Multimodal and hypertextual PowerPoint.
\end{abstract}

\footnotetext{
${ }^{1}$ Este artigo foi realizado com apoio financeiro da Fundação Araucária e se insere nas reflexões realizadas na pesquisa de mestrado (SCHACH, 2019) na Universidade Estadual do Oeste do Paraná (Unioeste) e na pesquisa de pósdoutorado realizada na Universidade do Estado do Rio de Janeiro (UERJ).

${ }^{2}$ E-mail: leticiaschach@gmail.com | ORCID: 0000-0001-9672-983X.

${ }^{3}$ E-mail: greicecastela@yahoo.com.br |ORCID: 0000-0002-9174-689X.
} 


\section{Introdução}

Como indica Faria (2019), já falamos hoje em Educação 4.0, ancorada na tecnologia e caracterizada pelo ensino híbrido (que mescla os elementos do ambiente educacional presencial com o on-line), pela cultura maker/learning by doing (aprender fazendo) e por metodologias ativas (que pressupõem o aprendiz como figura ativa, protagonista do seu aprender, a partir de metodologias como sala de aula invertida, aprendizagem baseada em problemas, aprendizagem entre times, aprendizagem baseada em projetos). Apesar disso, na prática, a escola não tem conseguido acompanhar as inovações tecnológicas que perpassam nosso dia a dia.

Para além disso, a escola também precisa lidar com diversas novas necessidades requeridas atualmente, como proporcionar ao aluno habilidade para dominar o letramento digital e, assim, poder de fato estar incluído na sociedade. Espera-se, não por último, que a escola colabore igualmente para a formação de cidadãos ativos, críticos, produtores de saberes. Desenvolver tais habilidades passa por múltiplos letramentos e pelos meios digitais, visto que estamos diante de um ser humano em uma nova concepção - usuário constante da tecnologia, da internet e, por consequência, mais ativo na sociedade, produtor e compartilhador de saberes -, bem como diante de uma nova concepção de sociedade. Segundo Faria (2019), a sociedade passa pela Quarta Revolução Industrial, com a linguagem computacional, a inteligência artificial e a internet, dinamizando os processos nos mais variados segmentos, em que justamente se espera que todo cidadão seja ativo. Conseguir ver nas Tecnologias Digitais de Informação e Comunicação (doravante TDICS) a possibilidade de a escola adentrar efetivamente o século XXI, juntando-se aos alunos no mundo que já vivenciam, é chave para uma mudança consistente quanto ao uso da tecnologia nas instituições de ensino.

Como afirma Moran (2008, p. 1), “A escola precisa reaprender a ser uma organização efetivamente significativa, inovadora, empreendedora. A escola é previsível demais [...], pouco estimulante para os bons professores e alunos". Assim, o autor explicita o quanto as escolas e universidades estão distantes das demandas atuais e apenas sobrevivem por serem espaços obrigatórios, legitimados pelo Estado. Já antes da virada do milênio, em 1996, o Grupo de Nova Londres escreveu um manifesto por uma pedagogia que levasse em conta formas múltiplas de letramentos e de multiletramentos, necessariamente incluindo a tecnologia e a multiculturalidade. De lá para cá, temos avançado lentamente em direção a uma efetiva inserção 
da tecnologia dentro da escola:

[...] tanto as tecnologias da cultura de massas (rádio e TV) como as da cultura das mídias (retroprojetores, episcópios, reprodutores de videocassete e de fitas cassete etc.) penetraram fraca, lateral e incidentalmente na escola e nunca foram incorporadas constitutivamente ao currículo e às práticas letradas escolares fundantes da cultura escrita e impressa (Rojo, 2017, p. 7).

Utilizar a tecnologia em sala apenas como fim em si mesma (como forma de variação, de diversão, de criação de movimento...) tem nos custado justamente este preço: o de não a vermos de fato inserida na escola como parte de um novo currículo. Lemke (2010, p. 471) diria que as árvores é que ficaram agradecidas, por ter sido poupado papel, mas pouco mudou em relação à natureza da aprendizagem, pois fizemos uma simples transposição do modelo de educação do livro-texto para uma nova mídia de demonstração. A título de exemplo, nós, professores, usamos o PowerPoint em aula, porém muitas vezes com slides em que o texto do próprio livro está simplesmente reproduzido; ou, se usamos imagens, elas geralmente são estáticas. Por razões como essa, para Rojo, está claro que "os multiletramentos ainda não adentraram a escola" (Rojo, 2017, p. 7), pois pouco temos considerado os textos multimodais contemporâneos, quase sempre digitais.

Entendida assim, a tecnologia precisa ser vista de outra perspectiva, de forma que seja apenas o meio para um novo paradigma educacional, em que as instituições de ensino não apenas eduquem os alunos para usar os recursos tecnológicos disponíveis, mas, sim, que usem a tecnologia para os processos de ensino e aprendizagem dos alunos. Não são as TDICs que vão reformular as nossas escolas: são os professores que, a partir delas, o farão. Isso, no entanto, demanda reflexão a partir das práticas atuais - além, claro, domínio técnico.

Partindo dessas reflexões, neste artigo nos propomos a refletir sobre possibilidades de efetivar a Pedagogia dos Multiletramentos, evidenciando o paradigma da aprendizagem interativa, que prevê um aluno ativo na construção do seu conhecimento. Para tanto, primeiro, refletimos sobre o paradigma da aprendizagem interativa e a Pedagogia dos Multiletramentos. Em seguida, realizamos para uma breve reflexão sobre multimodalidade e letramentos visual e digital. Depois abordamos o hipertexto como peça fundamental para a concretização de materiais didáticos digitais e interativos. Na sequência, apresentamos os procedimentos metodológicos adotados na pesquisa de Schach (2019), da qual este texto é parte. Por fim, analisamos um ODEA, observando se contempla os multiletramentos, especialmente a multimodalidade, por meio do 
software PowerPoint, em uma perspectiva multimodal e hipertextual.

\section{O paradigma da aprendizagem interativa e a Pedagogia dos Multiletramentos}

Em uma primeira parte dessa formação continuada, foram abordados conteúdos teóricos vinculados a tecnologias na educação e multiletramentos. Entendemos multiletramentos como "as práticas de trato com os textos multimodais ou multissemióticos contemporâneos majoritariamente digitais, mas também impressos -, que incluem procedimentos (como gestos para ler, por exemplo) e capacidades de leitura e produção que vão muito além da compreensão e produção de textos escritos, pois incorporam a leitura e (re)produção de imagens e fotos, diagramas, gráficos e infográficos, vídeos, áudio etc" (Rojo, 2017, p. 4). O conceito de multiletramentos engloba dois tipos de multiplicidade da contemporaneidade: a pluralidade cultural das populações e a multiplicidade semiótica de constituição dos textos por meio dos quais ela se comunica (Rojo e Moura, 2012).

Partimos do princípio de que existem hoje dois paradigmas de aprendizagem e educação em disputa na sociedade, sendo que as novas tecnologias devem mudar significativamente o equilíbrio entre eles (Lemke, 2010, p. 468). O primeiro paradigma é o da aprendizagem curricular: alguém decide o que você precisa saber e planeja como essa aprendizagem vai acontecer, definindo uma ordem e um cronograma fixos para isso. O segundo paradigma, o da aprendizagem interativa, ou colaborativa para Rojo (2012, p. 27), considera que cada pessoa determina individualmente o que precisa saber, a partir de uma necessidade percebida através da participação em atividades diversas. Além disso, cada um aprende na ordem, ritmo e tempo que ele próprio define. Não há uma imposição de fora.

Uma das razões para buscar a inclusão de um novo paradigma na educação, o da aprendizagem interativa, reside no fato de que o paradigma curricular tem falhado em diversos países. Muitos alunos não veem mais utilidade naquilo que aprendem nos bancos da escola, além de não estarem verdadeiramente preparados para aquilo que se espera de um adulto participante da sociedade atual. A nova ética e a nova estética requeridas passam pela escola por meio da Pedagogia dos Multiletramentos:

\footnotetext{
Aí se encontra um trabalho que a escola pode tomar para si: discutindo criticamente as 'éticas' ou costumes locais, constituir uma ética plural e democrática; discutindo criticamente as diferentes 'estéticas', constituir variados critérios críticos de apreciação dos produtos culturais locais e globais (Rojo, 2012, p. 28).
}

A Pedagogia dos Multiletramentos pode, assim, viabilizar professores conscientes das 
práticas de construção de significados na sociedade contemporânea. Para auxiliar nesta tarefa, o Grupo de Nova Londres propôs também princípios sobre como efetivar uma Pedagogia dos Multiletramentos, representados em um “mapa dos multiletramentos" (Figura 01).

Figura 01 - Mapa dos multiletramentos

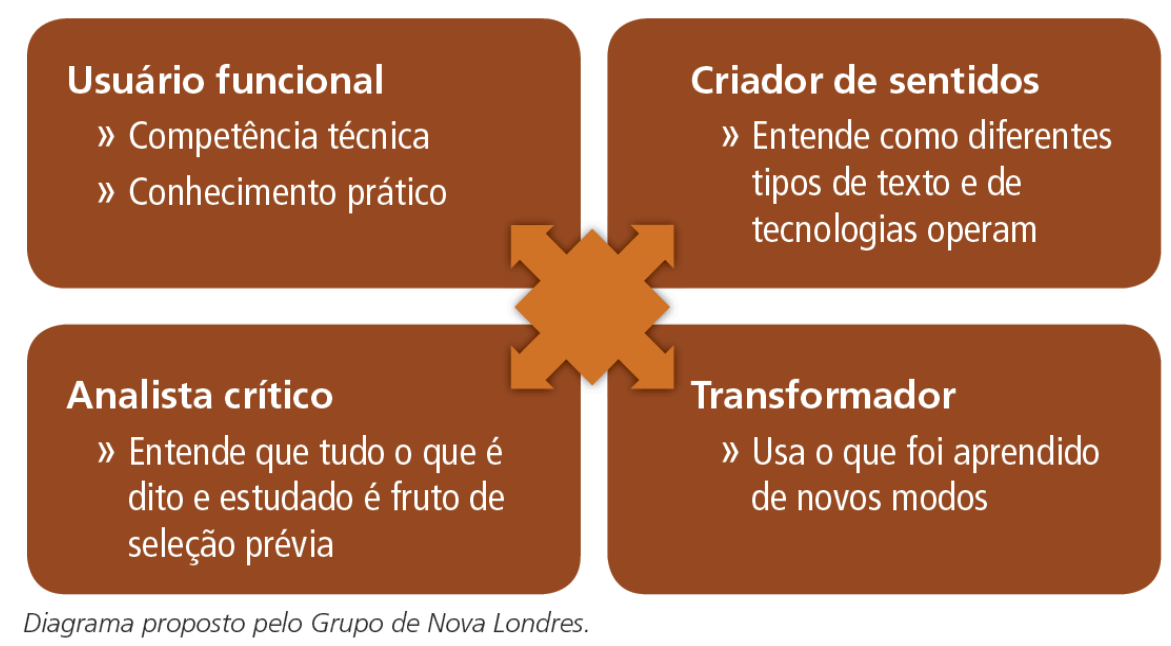

Fonte: Rojo (2012, p. 29).

Conforme esclarece Rojo (2012, p. 29), a intenção representada no diagrama acima é a de a escola formar um usuário funcional, com competência técnica nas diferentes práticas letradas, nos diferentes textos e ferramentas requeridas. Como garantir apenas esses "alfabetismos" não é o suficiente dentro da proposta da Pedagogia dos Multiletramentos, a escola precisa ainda trabalhar possibilidades práticas para que os alunos se transformem em criadores de sentidos. $E$ isso só é possível se eles forem analistas críticos, capazes de transformar os discursos e significações, tanto na recepção como na produção. Para que essa proposta descrita no diagrama proposto pelo Grupo de Nova Londres se torne real, a escola precisa garantir os diferentes letramentos necessários às práticas dos multiletramentos. Só nesta perspectiva tem-se alunos críticos, transformadores e criadores de sentidos.

As propostas de práticas pedagógicas do Grupo de Nova Londres condizem "com os princípios de pluralidade cultural e de diversidade de linguagens envolvidos no conceito de multiletramentos" (Rojo, 2012, p. 30), o que as torna uma prática desejável em nossas instituições de ensino, a fim de que estejam conectadas com uma educação contemporânea. Sendo assim, para tratar de forma mais aprofundada dessa diversidade de linguagens, abordamos o tema 
multimodalidade na sequência.

\section{Multimodalidade}

É consenso que os avanços tecnológicos influenciaram os modos de interação entre as pessoas, exigindo transformações nos eventos de escrita. Elementos visuais e sonoros passaram a compor os sentidos dos textos juntamente com os elementos verbais. Basta pensar na transmissão paralela de imagens durante uma ligação telefônica, via Skype, por exemplo, ou no uso de emoticons em uma conversa no WhatsApp ou post no Facebook. Imagens e palavras têm uma relação cada vez mais conectada. Segundo Vieira (2007), os textos contemporâneos requerem cores, sofisticados recursos visuais, e os aparatos tecnológicos, sons e movimentos, que se unem para construir novos sentidos. A multimodalidade - a presença de múltiplos modos de linguagem - é, portanto, um elemento que hoje integra tanto textos orais quanto escritos, sendo atualmente considerada um grande recurso construtor de sentido.

Concordamos com Xavier (2006) que os diferentes elementos que constituem um texto não podem ser compreendidos como formas justapostas, mas, sim, como partes que se unem de forma intencional na construção de um sentido completo. O que vemos na comunicação contemporânea é que sons, imagens, gestos, sinais, animações, detalhes gráficos, entre outros recursos semióticos, configuram a comunicação como um evento multimodal, que agrega diversos modos e recursos semióticos - tanto oralmente quanto por escrito, impresso ou digital. Por serem de fato constituintes de sentido, não meramente ilustrativos, está claro que as múltiplas formas de linguagem (os elementos não verbais especificamente) contribuem significativamente na intenção comunicativa.

Neste contexto, segundo Van Leeuwen, a multimodalidade se refere ao "uso integrado de diferentes recursos comunicativos, tais como linguagem, imagem, som e música em textos multimodais e eventos comunicativos" ${ }^{4}$ (Van Leeuwen, 2011, p. 668) - ou seja, imagem e elementos verbais têm funções distintas, se complementam, não significando uma simples substituição de um recurso pelo outro. Também Lemke concorda que

os significados das palavras e imagens [...] são diferentes em função dos contextos em que elas aparecem - contextos que consistem significativamente de componentes de outras mídias. Os significados em outras mídias não são fixos e aditivos (o significado da palavra mais o significado da imagem), mas, sim,

\footnotetext{
4 "[...] integrated use of different communicative resources, such as language, image, sound and music in multimodal texts and communicative events." (VAN LEEUWEN, 2011, tradução nossa)
} 
multiplicativos (o significado da palavra se modifica através do contexto imagético e o significado da imagem se modifica pelo contexto textual) fazendo do todo algo muito maior do que a simples soma das partes (Lemke, 2010, p. 456).

Estudioso da multimodalidade no Brasil, Vieira (2007) alerta para a necessidade de se considerar todos os elementos que compõem os textos no processo de leitura e atribuição de sentido. Para o autor,

o discurso multimodal ocupa espaço cada vez mais representativo nas práticas sociais contemporâneas. Nessa perspectiva, é impossível interpretar os modos semióticos prestando atenção somente na língua escrita ou oral, pois um texto deve ser lido em conjunção com todos os elementos semióticos dessa produção (Vieira, 2007, p. 54).

Assim, se vários modos são utilizados na produção de um texto, está claro que não é viável lê-lo focando apenas nos elementos verbais, já que estes são apenas um dos recursos semióticos usados na produção do texto e cada recurso utilizado traz novas informações. Desta maneira, constatamos que as diversas transformações referentes às práticas comunicativas das últimas décadas - especialmente em função das TDICs, que facilitam a combinação de diversas modalidades - introduziram novos modos de comunicação.

Além disso, torna-se necessário o desenvolvimento de diferentes habilidades, "criando uma nova área de estudos relacionada com os novos letramentos -digital (uso de tecnologias digitais), visual (uso das imagens), sonoro (uso de sons, de áudio), informacional (busca crítica da informação)- ou os múltiplos letramentos, como têm sido tratados na literatura" (Lorenzi e Pádua, 2012, p. 37). Conforme explica Rojo (2009), os letramentos múltiplos constituem "competências básicas para o trato com as línguas, as linguagens, as mídias e as múltiplas práticas letradas, de maneira crítica, ética, democrática e protagonista" (Rojo, 2009, p.119).

Ao considerarmos a abordagem da multimodalidade na análise dos ODEAs produzidos no estudo realizado, procuramos compreender a articulação dos diversos modos semióticos empregados em sua composição, observando, neste artigo científico, se o material didático proporciona ao aluno que desenvolva diferentes habilidades a partir dos letramentos digital e visual.

O letramento digital é compreendido por nós como a capacidade de usar as tecnologias digitais de maneira eficaz para a comunicação nas práticas sociais, culturais e educacionais. Este letramento habilita o sujeito a construir sentidos por meio do domínio de tecnologias de produção de texto escrito, imagético e sonoro (Castela, 2009). Rojo o define como 
um subconjunto dos multiletramentos, definido [...] pela 'nova' tecnologia (digital) adotada, mas não principalmente. O que define fundamentalmente os novos letramentos [...] é uma nova maneira de ver e de ser no mundo contemporâneo, que prioriza a interatividade, a colaboração e a (re)distribuição do conhecimento, ao invés da hierarquia, da autoria e da posse controlada e vigiada do conhecimento por diversas agências, como a escola, as editoras e a universidade (Rojo, 2017, p. 4).

Percebe-se, assim, a necessidade de ir além do letramento clássico, pois atualmente é necessário saber interpretar e criar sentidos, saber compartilhá-los, enfim, ter habilidades para interagir por meio das diversas formas mediadas pelas tecnologias digitais que inundam nossa sociedade.

Já o letramento visual é compreendido aqui como a capacidade de ler, compreender e usar as informações visuais para a comunicação. Está especialmente relacionado à compreensão da informação visual não simplesmente como um adendo aos elementos verbais, mas também como um elemento semiótico, que acrescenta sentido ao texto (Lemke, 2010, p. 461; Kress, 1998, p. 66).

Outro recurso que contribui para a efetivação dos multiletramentos é o hipertexto, sobre o qual nos ocupamos no item a seguir.

\section{Hipertexto}

Dentre as diversas possibilidades que contribuem para a materialidade da multimodalidade, o hipertexto, a hipermídia e os hiperlinks interessam-nos em especial. Os textos da contemporaneidade mudaram, exigindo assim novas competências de leitura e produção de textos para se participar das práticas de letramento atuais (Rojo, 2013, p. 8), entre elas, a habilidade de saber lidar com o funcionamento hipertextual dos textos contemporâneos. Assim, tratamos aqui do hipertexto e sua relação com as diversas linguagens que compõem um texto.

Os novos gêneros discursivos, como chats, posts, twits, acontecem hoje por dispormos de novas tecnologias e novas ferramentas. Os novos modos de significar e as novas configurações dos textos se valem das possibilidades hipertextuais, multimidiáticas e hipermidiáticas do texto eletrônico, constituindo textos multissemióticos (Rojo, 2013, p. 20). Para Lemke (2010), a origem disso está na linguagem digital, que reconfigura todas as modalidades de linguagem e mídias. As mídias digitais facilitam a modificação e combinação de conteúdos oriundos de quaisquer mídias: "[...] tão logo os textos online se tornem digitais (em oposição a imagens em bitmap da página), ele é facilmente pesquisável. E se pode ser pesquisável, pode ser indexado e estabelecer 
referência com outros textos. Agora, o texto é simultaneamente um banco de dados, e o hipertexto nasce" (Lemke, 2010, p. 471-472).

Como afirma Castela (2009, p. 58), o hipertexto

constitui uma estrutura possível em qualquer suporte, mas que é potencializada quando é produzida especificamente para o suporte eletrônico (CASTELA, 2003; 2008). É um modo de apresentação de informações, em um monitor de vídeo, em que são disponibilizadas conexões (links) entre determinadas passagens de um texto. Esses links se apresentam como elementos semioticamente ressaltados, seja palavra, expressão ou imagem, que, ao serem acionados, podem provocar a exibição de um outro (hiper)texto, texto, fragmento de texto, imagem, som ou vídeo com informações relativas ao elemento destacado.

Para Xavier (2004), o hipertexto é uma forma híbrida, dinâmica e flexível de linguagem que dialoga com outras interfaces semióticas, adiciona e acondiciona à sua superfície outras formas de textualidade. Especialmente por essa razão, pode ser compreendido como potencial ferramenta de ensino-aprendizagem, pois possibilita que o aluno participe de fato, de forma ativa, da construção do seu saber. Ele dinamiza a postura do leitor, visto que o permite optar por caminhos distintos, que podem seguir ou retornar de acordo com sua escolha (Koch, 2007).

Kenski aponta na mesma direção ao confirmar que "A base da linguagem digital são os hipertextos, sequências em camadas de documentos interligados, que funcionam como páginas sem numeração e trazem informações variadas sobre determinado assunto" (Kenski, 2012, p. 33). Assim, justamente por não serem paginadas/ordenadas, as diferentes páginas, ou informações disponibilizadas, são acessadas conforme a ação individual de cada pessoa, que pode, ou não, aprofundar o nível das informações sobre determinado assunto.

Fundamental é perceber a relevância do hipertexto e da hipermídia no contexto da aprendizagem, pois, conforme Lemke (2010, p. 472), com eles

[...] a aprendizagem muda. Ao invés de sermos prisioneiros de autores de livros texto e de suas prioridades, escopos e sequência, somos agentes livres que podem encontrar mais sobre um assunto que os autores sintetizaram, ou encontrar interpretações alternativas que eles não mencionaram (ou com a qual concordam ou até mesmo consideram moral ou científico). Podemos mudar o assunto para adequá-lo ao nosso juízo de relevância para nossos próprios interesses e planos e podemos retornar mais tarde para um desenvolvimento padrão baseado no livro texto. Podemos aprender como se tivéssemos acesso a todos estes textos e como se tivéssemos um especialista que pudesse nos indicar a maioria das referências entre tais textos. Temos agora que aprender a realizar formas mais complexas de julgamento e ganhamos muita prática fazendo isso. 
Ao ter acesso a um hipertexto, o leitor não precisa ler tudo o que está na tela para só depois seguir em frente. $O$ hipertexto the permite avançar, a qualquer momento, entre as diferentes informações disponíveis, conforme seu interesse. Além disso, outros caminhos se abrem a partir da hipermídia: "Se no meio desse encadeamento de textos houver outras mídias fotos, vídeos, sons etc. -, o que se tem é um documento multimídia ou, como é mais conhecido, uma hipermídia" (Kenski, 2012, p. 33). Por meio da hipermídia, hipertexto e recursos midiáticos se reúnem, e o leitor pode assistir a um vídeo, ver fotos, acessar infográficos, ouvir áudios, ler outro texto, enfim, acessar informações em uma variedade infinita de formatos. Importa, aqui, que é o leitor quem define o caminho que quer seguir.

A junção de hipertexto e recursos midiáticos, gerando a hipermídia, pode ser compreendida como uma organização em uma rede de nós, conectados por ligações denominadas hiperlinks. Isso amplia ainda mais a noção de multimodalidade. Os hiperlinks, ou links, são termos sublinhados ou em destaque no hipertexto eletrônico que estabelecem ligação com outros textos. Chamam a atenção do leitor, indicando que há algo além do que se vê, possibilitando que se inicie um novo processo interativo. Assim, por fomentarem a interação entre texto e leitor, tanto o hipertexto quanto a hipermídia, quando utilizados em contexto educacional, muito mais do que apenas diversificam a aula; eles promovem a visão crítica do aluno, seja por ler aquilo que lhe interessa, seja por manusear múltiplas semioses. Neste contexto, a informação passa a conhecimento, favorecendo, assim, novas aprendizagens.

O hipertexto ou a multimídia interativa adequam-se particularmente aos usos educativos. É bem conhecido o papel fundamental do envolvimento pessoal do aluno no processo de aprendizagem. Quanto mais ativamente uma pessoa participar da aquisição de um conhecimento, mais ela irá integrar e reter aquilo que aprender. Ora, a multimídia interativa, graças à sua dimensão reticular ou não-linear, favorece uma atitude exploratória, ou mesmo lúdica, face ao material a ser assimilado. É, portanto, um instrumento bem adaptado a uma pedagogia ativa (Lévy, 2004, p. 24).

Isso posto, temos que a multimodalidade, o hipertexto e os gêneros digitais, viabilizados pelas TDICs, são de grande relevância para a área da educação, pois fomentam diversas possibilidades de interação, comunicação, socialização, discussão e flexibilidade. No caso da educação linguística, é possível mais do que estimular os alunos para além da leitura e interpretação; eles são estimulados a analisar, relacionar e criticar, construindo, assim, sua 
aprendizagem de modo autônomo e significativo.

A facilidade de manipulação de dados diversos (imagens, sons etc.) por meio de ferramentas computacionais favorece a produção de materiais didáticos digitais. Com a inserção de diferentes recursos semióticos, os materiais estão cada vez mais multimodais; com os hiperlinks e hipertextos, ampliam as informações e reorganizam o design gráfico dos textos e, por consequência, possibilitam a aquisição de conhecimento a aprendizagem. Assim, é inevitável perceber a potencialidade da multimodalidade e dos hipertextos para a aprendizagem, promovendo a visão crítica do aluno.

Retornamos, por fim, à distinção de dois tipos de aprendizagem feita por Lemke (2010, p. 461), enfatizando que é muito mais significativo o paradigma da aprendizagem interativa, em que cada pessoa determina o que precisa saber, na ordem que the cabe e no ritmo que lhe for confortável. Concordamos, com o autor, pois acreditamos que precisamos, enquanto escola, acompanhar a sociedade contemporânea digital em que estamos, usufruindo das possibilidades que a multimodalidade, o hipertexto e a hipermídia nos disponibilizam, buscando esse paradigma que prioriza o acesso à informação, muito mais do que o da imposição à aprendizagem. $E$, dentro das práticas pedagógicas de um novo paradigma, encaixam-se perfeitamente, por exemplo, os ODEAs desenvolvidos durante a formação continuada realizada. Passamos a seguir a apresentação dos procedimentos metodológicos da pesquisa.

\section{Procedimentos metodológicos}

Consideramos que o papel do professor se reconfigura a partir dos multiletramentos: ele evolui daquele que ensina para aquele que igualmente aprende e co-aprende, promovendo, assim, a aprendizagem de forma colaborativa e interativa. Nesta perspectiva, o docente orienta e conduz o aprendiz em seu caminho individual de construção do saber, contribuindo para o desenvolvimento de competências, de habilidades e da cidadania.

Para vir ao encontro de tais reflexões, fizemos a opção por trabalhar a partir de um curso de formação docente continuada, intitulado "Multiletramentos na Prática: PowerPoint Avançado para o Trabalho com Contos de Aventura", com 40 horas, que ofertamos, em 2018, no município de Marechal Cândido Rondon, no Paraná. Participaram do curso 5 professores da rede pública de ensino que atuam na disciplina de língua portuguesa nos níveis de ensino fundamental e médio, tendo cada um elaborado um ODEA utilizando um conto de aventura de sua escolha. 
Essa formação foi organizada de modo a possibilitar integração entre discussões teóricas (sobre multiletramentos e Pedagogia dos Multiletramentos; TDICs na educação; formação docente; objetos digitais de ensino-aprendizagem e repositórios digitais; formação para uso da ferramenta PowerPoint; gênero discursivo conto de aventura; e concepções de leitura) e prática de elaboração de materiais didáticos digitais por meio do software PowerPoint em uma perspectiva hipertextual e multimodal. Os primeiros encontros foram dedicados a uma abordagem mais teórica, a fim de trabalhar com os professores os fundamentos das tecnologias na educação e dos multiletramentos; a partir disso, conhecemos ODEAs e repositórios digitais, para cogitar possibilidades. Na sequência, retomamos conhecimentos quanto ao tipo narrativo e gênero conto de aventura, selecionando, a partir disso, contos para a produção dos ODEAs. Com alguns contos deste gênero escolhidos, os professores foram instrumentalizados para o uso do PowerPoint em modo básico (criação de apresentações personalizadas, inserção de imagens, uso de animações, transições, alteração de aspectos estéticos, etc) e avançado (uso de hiperlinks, inserção de vídeos e áudios, criação de movimento com trajetórias de animação, etc). Os docentes produziram seus próprios ODEAs com percursos de leitura, recursos e atividades a partir do programa trabalhado no curso. Por fim, criados os ODEAs, cada professor fez sua catalogação e inserção em um repositório digital.

A partir da exploração de um gênero discursivo específico - o conto de aventura - e do aprendizado para o uso, em nova perspectiva, de uma ferramenta tecnológica - PowerPoint -, os sujeitos da formação continuada criaram materiais didáticos digitais ${ }^{5}$ que exploram a leitura de forma multimodal, contemplando, assim, os multiletramentos. Tais materiais são denominados mais especificamente como Objetos Digitais de Ensino-Aprendizagem (doravante ODEAs): materiais didáticos digitais (arquivos multimídia como videoaulas, jogos virtuais, animações...) utilizados como apoio à prática pedagógica, tanto em sala de aula como também fora dela. Tais recursos educacionais caracterizam-se por seu caráter interativo, dinâmico e motivador ao processo educativo. Especialmente por seu caráter interativo, os ODEAs possibilitam que os alunos participem ativamente do processo de construção do seu conhecimento. São recursos reutilizáveis, que são catalogados e armazenados em repositórios digitais, facilitando o compartilhamento.

Para a produção dos ODEAs durante a formação continuada, definimos o software de

\footnotetext{
5 Tanto os encontros da formação docente continuada quanto os ODEAs produzidos durante a pesquisa estão disponíveis em: encurtador.com.br/HQZ45.
} 
apresentação multimídia PowerPoint, entre outras razões, por ser uma ferramenta que possibilita a criação de materiais que podem configurar por excelência documentos multimodais, inclusive bastante sofisticados em termos de layout, pois integram com facilidade texto verbal e não verbal, imagens, vídeos e elementos sonoros, que se combinam entre si, criando novos significados.

Já para o recorte deste artigo definimos como objeto de análise apenas um dos ODEAs criados durante a formação continuada realizada. Este foi selecionado em função da sua qualidade e da observância dos elementos solicitados, a saber: produção de objeto efetivamente digital; propostas de atividades que possibilitassem o uso da hipertextualidade; confecção de material didático multimodal, com inserção de diferentes modos e recursos semióticos, provocando uma reorganização da produção do conhecimento, e promoção da Pedagogia dos Multiletramentos (professor mediador e aluno sujeito). Na análise, realizada este artigo, observamos se este ODEA contempla os multiletramentos a partir da presença de elementos multimodais e hipertextuais. Mais especificamente, objetivamos confirmar se há presença de elementos que promovam os letramentos visual e digital do aluno, fomentando seu protagonismo durante o processo de aprendizagem.

A pesquisa, aqui descrita, insere-se na Linguística Aplicada, sendo uma pesquisa qualitativa que realiza análise documental desse ODEA. Realizamos, a seguir, a descrição e análise do ODEA selecionado.

\section{Análise do ODEA e resultados}

Os ODEAs produzidos durante a pesquisa são arquivos criados com o programa PowerPoint, porém não com a intenção de servir como uma apresentação de slides, como normalmente são conhecidos arquivos em formato PPT, mas, sim, como material de apoio para a exploração da leitura de contos de aventura. Assim, podem ser utilizados tanto em sala de aula como em casa, de forma autônoma pelo aluno, para aprofundamento ou ampliação do que foi trabalhado no espaço escolar. É importante mencionar que eles são materiais interativos, nunca meramente expositivos de um determinado conteúdo, visto que sempre demandam a participação ativa do aprendiz e só funcionam a partir da sua interação.

Também é válido mencionar que não é possível compreender o ODEA apresentado na sequência em que os slides aparecem. Como é um material multimodal, dinâmico e que demanda interatividade, conforme o slide em que se está, ao clicar, opta-se por um de mais possíveis 
caminhos. Assim, o aluno é conduzido a um slide ou outro, a partir de suas escolhas. Cada aluno, desta forma, opta pessoalmente pela sequência que deseja seguir. Cada experiência com um dos ODEAs, portanto, é única.

Nesta seção, dedicamo-nos, então, a apresentar um dos ODEAs produzidos ${ }^{6}$ por uma das professoras participantes do curso de formação continuada, a qual demos o nome fictício de Mara para garantir seu anonimato. Este ODEA, intitulado "As três maçãs de ouro", foi construído a partir do conto baseado na obra de Nathaniel Hawthorne. O conto narra a busca do lendário herói Hércules por três maçãs de ouro que cresciam no jardim de Hespérides, que pertencia a três ninfas, filhas de Atlas, titã condenado por Zeus a sustentar o mundo nos ombros por toda a eternidade. Durante o conto, além de se defrontar com Atlas, Hércules precisa encarar diversos obstáculos que vão constituindo sua grande aventura, enfrentando Nereu, o velho do mar, e auxiliando na libertação de Prometeu.

Ainda que só tenha 15 slides, o ODEA instiga muito a participação e criatividade do aluno, pois apresenta constantemente atividades que exigem muita ação e interatividade. Em todos os slides é demandada alguma ação do aluno, de forma que a história avance - e consequentemente os slides. O ODEA apresenta sempre muitas imagens, com cenários completos e de alta qualidade, com vários elementos diferenciados, como a narração de um trecho da história (gravada pela própria autora do ODEA), o redirecionamento para fora da apresentação a partir de hiperlinks, conduzindo para sites de leitura do conto, ou atividades vinculadas à história. Ainda, há um arquivo de escrita virtual disponível para que seja acessado pelo aprendiz.

Um primeiro critério observado no ODEA está vinculado à promoção do letramento visual. É percebido principalmente por meio da apresentação das informações em uma mescla de diferentes modos e recursos semióticos presentes nas atividades (junção de texto verbal, imagens estáticas, imagens em movimento etc.). Na figura 02, por exemplo, temos o primeiro slide do ODEA, que não traz o título em texto verbal, mas, sim, com imagens: o aluno vê três maçãs de ouro, justamente o título do conto. Ao abrir o ODEA, as três maçãs inclusive aparecem em movimento.

Figura 02 - Slide 1 do ODEA analisado

\footnotetext{
${ }^{6}$ Disponível, na íntegra, em: encurtador.com.br/iAJT3.
} 


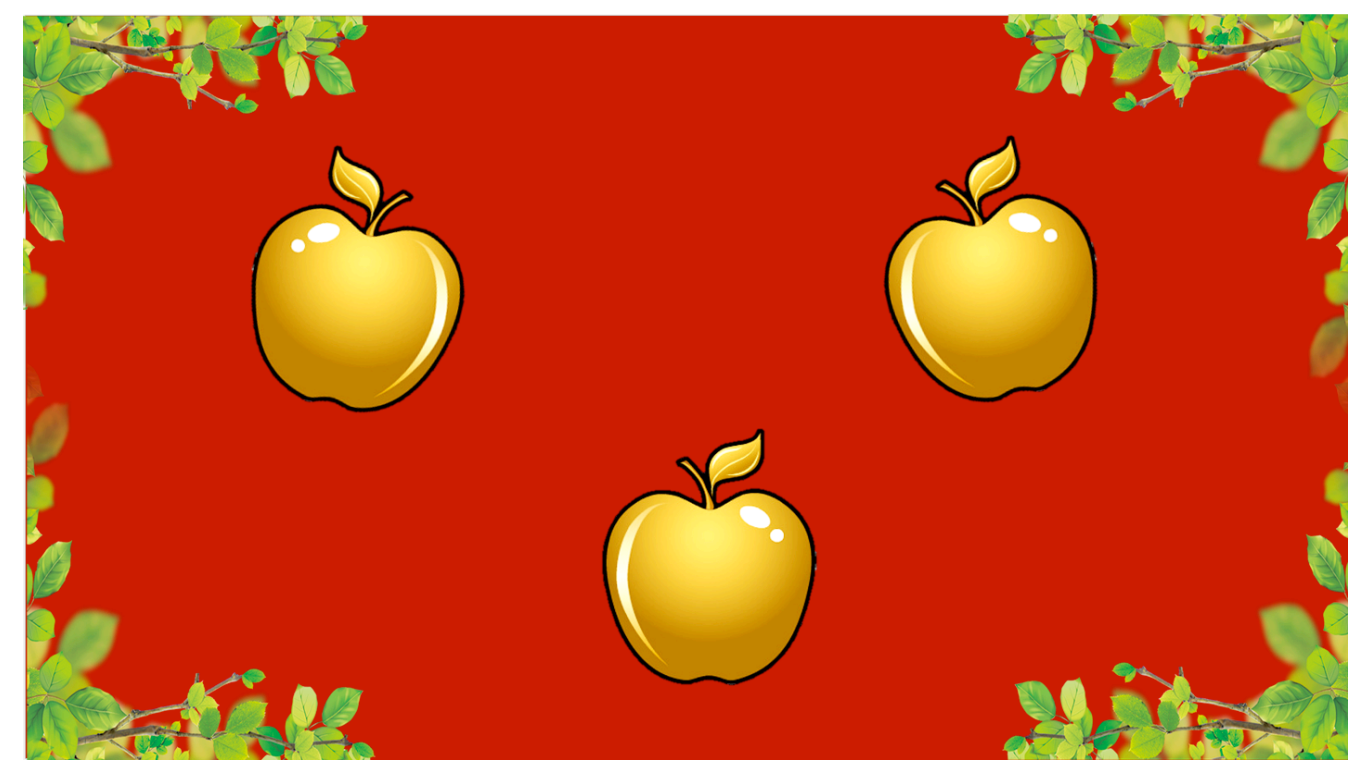

Fonte: ODEA produzido por Mara

Como afirma Lemke (2010, p. 461-462), o texto verbal não necessariamente é "a espinha organizadora de um trabalho multimidiático". O autor enfatiza que a combinação de diferentes modalidades semióticas é mais do que a soma do que cada parte pode significar separadamente, o que ele chama de "significado multiplicador". Neste sentido, quando pensamos em multimídia, em multissemioses, as possibilidades de significação são multiplicadas, não meramente aditivas. 0 ODEA em análise apresenta diversos exemplos da multissemiose característica para o letramento visual.

Na Figura 03, temos mais um exemplo que demonstra como o ODEA pode possibilitar o letramento visual. Neste ODEA, após receber a informação, em um slide anterior, de que precisa "andar por todo o mundo" para encontrar a macieira e as três maçãs de ouro, Hércules surge no próximo slide ao lado de uma mala vazia, rodeado por elementos que caracterizam uma bagagem (pente, relógio, mapa). Arco e flecha, espada e corda contribuem aqui para o aluno ter a sensação de que está embarcando em uma viagem de aventura.

Figura 03 - Slide 3 do ODEA analisado 


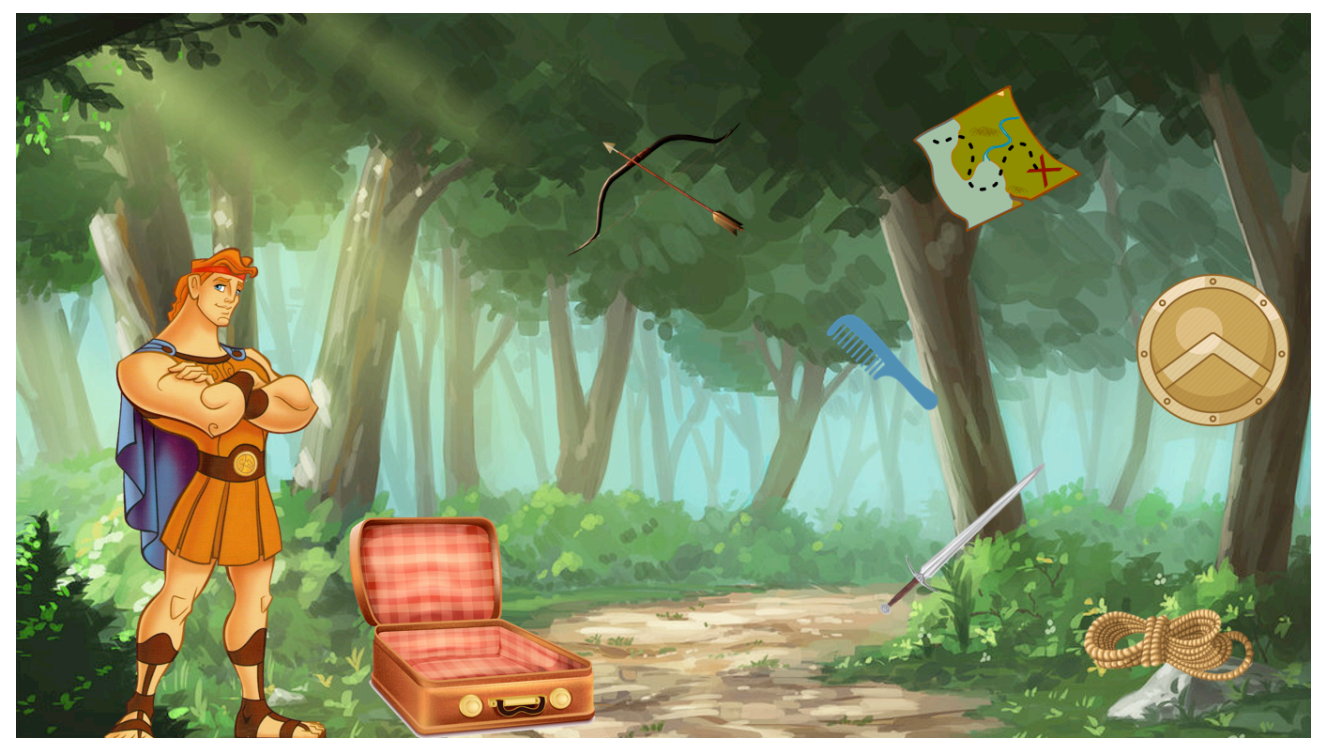

Fonte: ODEA produzido por Mara

A necessidade de letramento visual é percebida na Figura 03 por não haver instrução alguma ao aluno por meio de texto verbal. Ele precisa olhar a cena e deduzir, ativando suas habilidades quanto ao letramento visual, que deve clicar nos elementos soltos para colocá-los na mala, o que faz com que o protagonista esteja então pronto para iniciar sua aventura e o aluno, pronto para avançar ao próximo slide. Fica claro, assim, que, para compreender a função dos elementos soltos na imagem, e ativá-la, é preciso ser competente nos letramentos multissemióticos, aqui especificamente em relação ao campo da imagem.

Outro exemplo em que se percebe que não é o texto verbal que forma a "espinha organizadora do trabalho multimidiático", conforme nomeado por Lemke (2010, p. 462), está na Figura 04.

Figura 04 - Slide 13 do ODEA analisado 


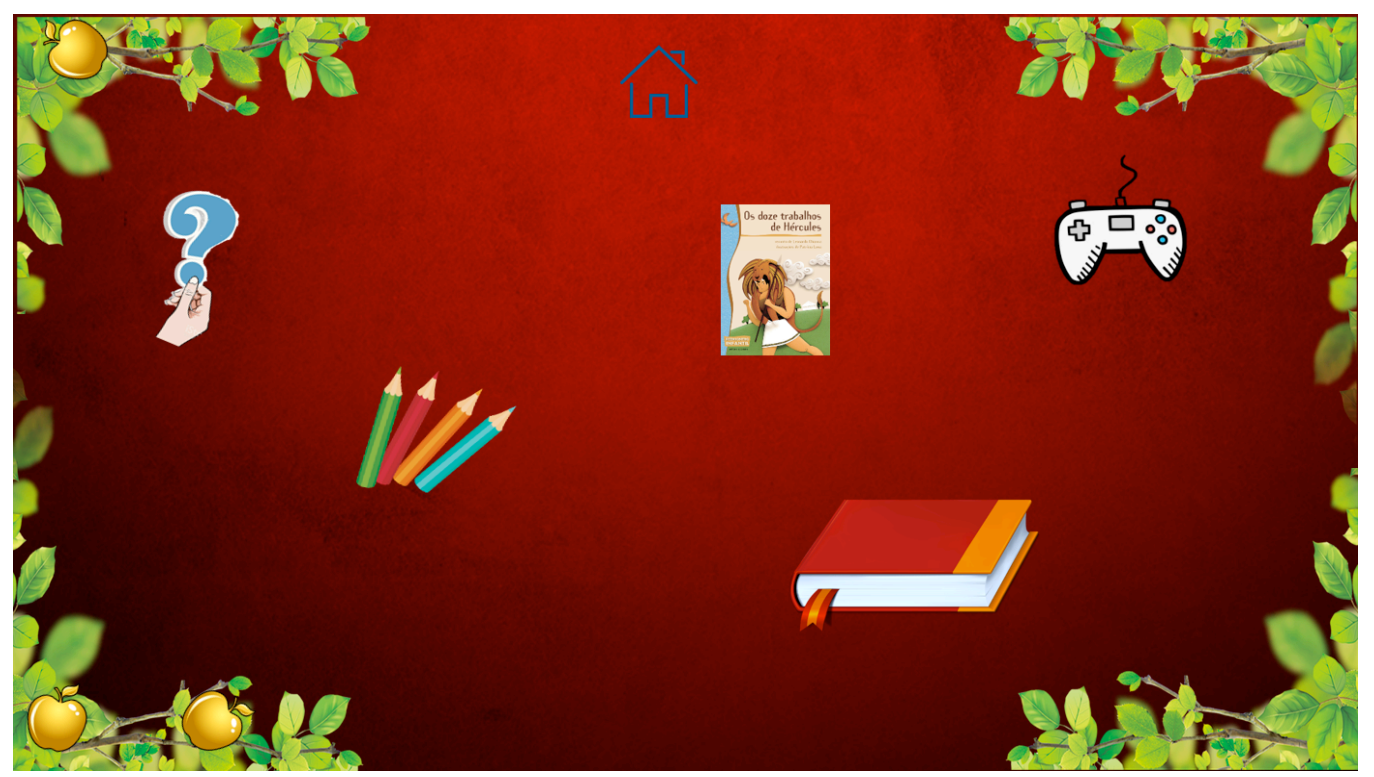

Fonte: ODEA produzido por Mara

Ao chegar neste slide (13), o aluno não recebe informação verbal, então precisa trabalhar ativando seu letramento visual. Há cinco imagens distintas no slide, e cada uma delas tem "escondida" em si um hiperlink, que direciona o aluno a outros lugares. O ponto de interrogação leva a outro slide, que propõe questões para discussão em grupo, e esse slide leva depois a um documento de edição de texto, em nuvem, em que a turma pode registrar por escrito o que discutiu. Os lápis de cor conduzem a um site com imagens de Hércules para serem coloridas digitalmente. A capa do livro, a um arquivo em PDF com a obra completa (já que o ODEA não apresenta em nenhum momento o texto, a história em si, por completo). O livro no canto inferior direito abre um novo slide com a imagem de um livro com uma pergunta e linhas vazias para a resposta, o que induz o aluno a responder a pergunta "por escrito" (o que ele fará ao clicar no livro, sendo então levado a um documento virtual, em nuvem, para registrar sua resposta por escrito). Por fim, ao clicar no joystick, o aluno é conduzido a um site com jogos sobre o personagem Hércules.

Com esses exemplos, constatamos a promoção do letramento visual no ODEA apresentado, que funciona perfeitamente quando o aluno adiciona a informação recebida por meio de texto verbal à informação vinda de uma imagem; ou, em outros casos, onde uma imagem não é meramente somatória, mas, sim, traz significado por si só. Para Rojo, a educação linguística promovida pela escola hoje precisa considerar

os letramentos multissemióticos exigidos pelos textos contemporâneos, 
ampliando a noção de letramentos para o campo da imagem, da música, das outras semioses que não somente a escrita. $O$ conhecimento e as capacidades relativas a outros meios semióticos estão ficando assim cada vez mais necessários no uso da linguagem, tendo em vista os avanços tecnológicos: as cores, as imagens, os sons, o design etc. [...] (Rojo, 2009, p. 107).

Nesta análise, norteiam-nos também critérios que consideram as ações de interatividade inseridas nos ODEAs - passagem de slides, acesso a outros slides ou outros textos através de hiperlinks, cliques para escolher alternativas de respostas ou fazer opções, movimentos com o mouse para mover palavras ou objetos, produção textual em meio digital. Todos esses elementos são formas de promover o letramento digital.

Começamos mencionando a capacidade de avançar de um slide a outro, necessária, por exemplo, em praticamente todos os slides do ODEA analisado. Muitas vezes, não há indicação de como avançar, nem mesmo uma seta - ou seja, o aluo precisa se dar conta de que é preciso mover o mouse até encontrar um elemento clicável e, assim, fazer o slide avançar. Vemos isso, por exemplo, na Figura 03, em que, após colocar todos os elementos na mala (clicando em cada um deles, o que também demanda letramento digital), nada acontece se o aluno não movimentar o mouse e assim perceber que pode clicar na personagem. Ela é a chave para o avanço do slide. Ou seja, sem ser digitalmente letrado, é impossível interagir nesse slide.

Outra forma de fomentar o letramento digital está no acesso a outros slides ou textos externos através de hiperlinks, elemento que aparece, por exemplo, na Figura 04 (cada elemento visual corresponde a um link ali deixado pela autora do ODEA). O uso de hiperlinks é bastante útil na promoção dos multiletramentos, já que leva o aluno, enquanto navegador, à posição de coautor, pois cada trajetória, cada forma de percorrer o ODEA é única. Outro aluno utilizando o mesmo ODEA percorrerá outro caminho, configurando outra leitura do mesmo material. Como os hiperlinks são apenas possibilidades deixadas pelo autor do ODEA, o aluno tem um papel muito mais ativo do que quando manuseia um material didático impresso. Por esta razão, segundo Xavier (2009), o hipertexto configura uma forma de emancipação do leitor em relação ao autor.

A possibilidade de escolher por qual caminho seguir, em que ordem, é uma experiência bastante distinta da experiência de leitura de um texto impresso desse gênero, pois este já tem sua trajetória definida. Diferente do uso de um material didático impresso tradicional, em que o aluno recebe uma trajetória pré-determinada, com um material multimodal ele tem diante de si um caminho imprevisível, que o torna mais convidativo. É o aluno quem faz as escolhas, que o vão conduzindo por caminhos novos e, provavelmente por isso, instigantes. "Cabe ao leitor, durante a 
leitura, determinar - com base em seu interesse, curiosidade, conhecimento prévio, ou tarefa de leitura tanto a ordem de acesso às diferentes secções textuais, quanto o eixo coesivo que confere sentido ao texto lido" (Braga, 2003, p. 80). Tal característica também torna efetiva a abordagem dos multiletramentos em um ODEA, pois ele possibilita que o aluno seja ativo no processo de construção do seu conhecimento. Conforme Xavier,

A não-linearidade está prevista já mesmo em sua concepção. Essa tecnologia enunciativa assume a deslinearidade em sua arquitetura inicial e o produz com vários links que podem levar seus usuários a percorrer diferentes infovias. Por essa razão, a abordagem de um hipertexto sempre será diferente, ainda que seja feita pelo mesmo usuário (Xavier, 2009, p. 123).

Neste ODEA hipertextual e multimodal a ordem de acionamento dos links não compromete a compreensão do todo, já que foram criados para um processo de leitura não linear. $E$, se o aluno utilizar de novo o mesmo ODEA, é possível que a experiência seja mais uma vez diferente - o que faz com que um material multimodal seja instigante e desafiador.

Por fim, mais um exemplo característico da multimodalidade está na Figura 05: a ausência de texto verbal precisa ser superada pelo aluno, que movimentará o mouse para descobrir o que deve fazer, a fim de que a história avance.

Figura 05 - Slide 11 do ODEA analisado

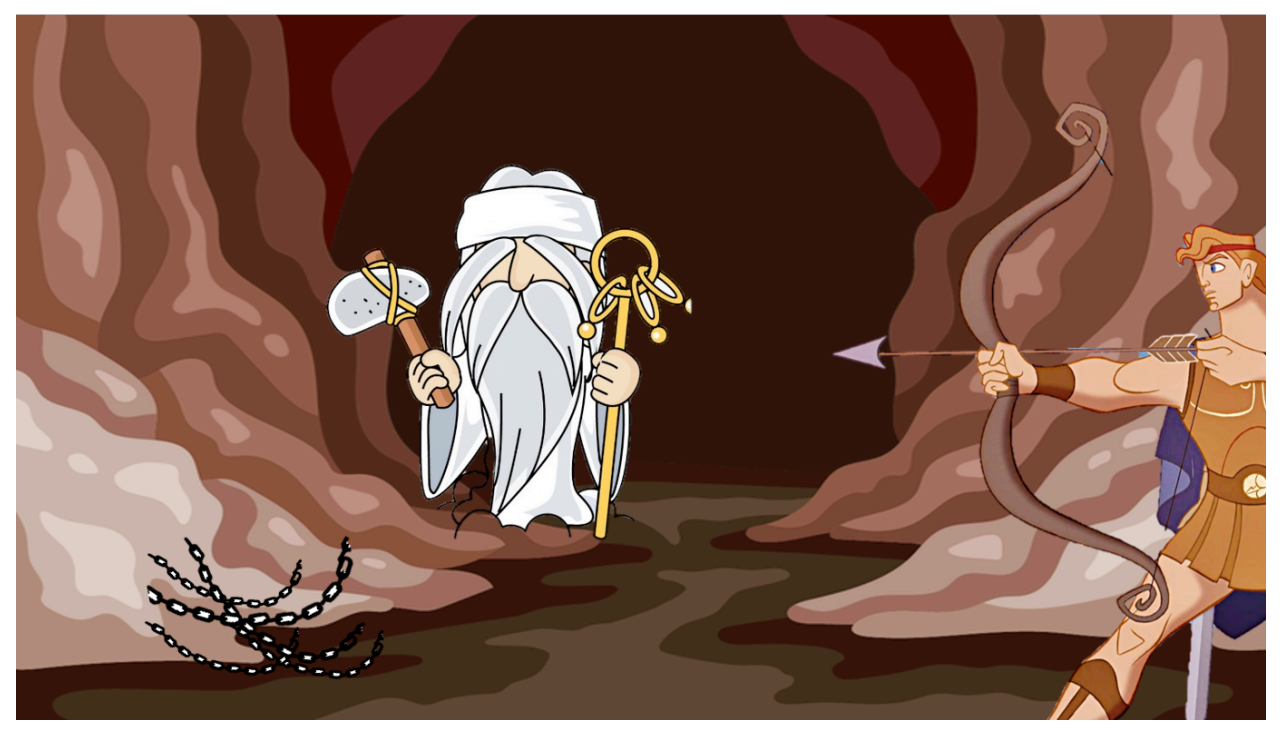

Fonte: ODEA produzido por Mara

Este ODEA exige interatividade o tempo todo, pois a evolução da história depende da 
ação do estudante. Já no início do ODEA, este vai compreendendo que assume a posição de Hércules, como se fosse o próprio personagem. Assim, quando chega no slide da Figura 05, pela sequência da história, o estudante sabe que precisa aprisionar o personagem que ali aparece para que the repasse determinada informação. Ao clicar em cada uma das correntes (à esquerda, embaixo), percebe-se que, uma a uma, inclusive com sons de correntes sendo arrastadas, elas vão como que prendendo o personagem que ali aparece - que, por fim, fica todo acorrentado e informa, enfim, o que Hércules - papel assumido pelo aluno - precisa saber para seguir adiante/continuar a história. Este é um exemplo muito completo e eficaz de trabalho multimidiático, com promoção do letramento visual - em que imagem e texto verbal se complementam -, do letramento digital e presença de multissemioses, por exemplo, por meio da junção do som às imagens e, depois, ao texto escrito.

Por tudo isso, verificamos que este ODEA apresenta riqueza quanto ao enfoque multissemiótico, constatando, assim, que efetivamente explora os multiletramentos ao abordar os letramentos visual e digital.

\section{Considerações finais}

A análise feita demonstra que o ODEA em questão é perpassado por atividades que promovem, em diversos aspectos, os letramentos visual e digital. Percebe-se que a professora que o criou, após um trabalho dedicado e minucioso, perseguiu sempre a intenção de possibilitar ao aluno que, ao acessar o ODEA, tivesse em mãos um material efetivamente multimodal, em que ele, conduzido por um material formulado pelo professor, seria peça fundamental na construção do seu conhecimento.

Quanto ao letramento visual, foi possível perceber em diversos aspectos sua promoção, visto que não encontramos, ao lado de uma imagem que "diz tudo", a "tradução" verbal da informação. Se consideramos as ações de interatividade do aluno com a máquina, percebemos também uma efetiva promoção do letramento digital, pois há poucas similaridades entre as atividades analisadas e atividades que pudessem ser realizadas no papel/no caderno. Todas elas de fato exigem o letramento digital do aluno, promovendo assim a interatividade e os multiletramentos.

Constatamos, de igual modo, que as TDICs de que disponibilizamos hoje para produzir e editar textos propiciam uma ampla combinação de diferentes modos de representação, de texto 
verbal, sons e imagens, tanto estáticas como em movimento, facilitando o trabalho do professor, neste caso específico, promovendo satisfatoriamente os multiletramentos.

Podemos, enfim, afirmar que o ODEA analisado de fato contempla os multiletramentos, e de forma muito eficaz, visto que apresenta os desejados aspectos vinculados à multiplicidade de linguagens, integrando a multimodalidade em um PowerPoint multimodal e hipertextual e, mais do que isso, fomentando o desejado protagonismo de um aluno do século XXI.

\section{Referências}

BRAGA, D. A natureza do hipertexto e suas implicações para a liberdade do leitor e o controle do autor nas interações em ambiente hipermídia. Revista ANPOLL, n. 15, 2003. São Paulo, FFLCH/USP.

CASTELA, G. da S. A leitura e a didatização do (hiper)texto eletrônico no ensino de espanhol como língua estrangeira (E/LE). Rio de Janeiro: UFRJ, Faculdade de Letras, 2009. 252 páginas. Defesa da Tese de doutorado Letras Neolatinas. Disponível em: < https://ensinodelinguascomtic.files.wordpress.com/2012/09/castella_2009_tese.pdf $>$. Acesso em: 06 nov 2019.

FARIA, M. Bits e Bytes - A educação nunca mais foi a mesma, e nem será... Linha direta na gestão educacional. Ed. 254, ano 22, maio 2019, p. 16-20.

KENSKI, V. M. Educação e tecnologias: O novo ritmo da informação. 8. ed. Campinas: Papirus, 2012. (Coleção Papirus Educação)

KOCH, I. V.; ELIAS, V. M. Ler e compreender: os sentidos do texto. 2. ed. São Paulo: Contexto, 2007.

KRESS, G. Visual and verbal modes of representation in electronically mediated communication. In: SNYDER, I. (ed). Page to screen: talking literacy into electronic era. New York: Routledge, 1998. p. 53-79.

LEMKE, J. Letramento metamidiático: Transformando significados e mídias. Trabalhos em Linguística Aplicada, Campinas, SP, v. 49/2, p. 1-17, 2010. Disponível em: $<$ http://www.scielo.br/scielo.php?script=sci_arttext\&pid=S0103-

$18132010000200009 \&$ Ing=en\&nrm=iso\&tlng=pt >. Acesso em: 18 abr 2019.

LÉVY, P. As tecnologias da inteligência. O futuro do pensamento na era da informática. Trad. Carlos Irineu da Costa. São Paulo: Editora 34, 2004.

LORENZI, G. C. C.; PÁDUA, T. W. de. Blog nos anos iniciais do fundamental I: a reconstrução de sentido de um clássico infantil. In: ROJO, R.; MOURA, E. (org.). Multiletramentos na escola. São Paulo: Parábola, 2012.

MORAN, J. M. Aprendizagem significativa. In: Portal Escola Conectada, Fundação Ayrton Senna. Disponível em: < www.escola2000.org.br/comunique/entrevistas/ver_ent.aspx?id=47 >. Entrevista publicada em 01/08/2008. Acesso em: 02 ago 2019.

ROJO, R. Entre plataformas, ODAs e protótipos: novos multiletramentos em tempos de web 2. The ESPecialist: Descrição, Ensino e Aprendizagem, v. 38, n. 1, p. 1-20, jan./jul. 2017. Disponível em: <https://revistas.pucsp.br/index.php/esp/article/view/32219>. Acesso em: 29 jul 2019. 
(org.). Escol@ conectada: os multiletramentos e as TICs. São Paulo: Parábola, 2013.

. Letramentos múltiplos, escola e inclusão social. São Paulo: Parábola Editorial, 2009.

ROJO, R.; MOURA, E. (org.). Multiletramentos na escola. São Paulo: Parábola, 2012.

SCHACH, L. A abordagem dos multiletramentos na criação de objetos digitais de ensinoaprendizagem com o PowerPoint. 2019. Dissertação (Mestrado em Letras) - Universidade Estadual do Oeste do Paraná, Cascavel, 2019.

VAN LEEUWEN, T. Multimodality. In: SIMPSON, J. (ed.) The outledge handbook of applied linguistics. New York: Routledge, 2011.

VIEIRA, J. A.; ROCHA, H. da; MAROUN, C. B.; FERRAZ, J. de A. Reflexões sobre a língua portuguesa: uma abordagem multimodal. Petrópolis: Vozes, 2007.

XAVIER, A. C. dos S. A era do hipertexto: linguagem e tecnologia. Recife: Ed. Universitária da UFPE, 2009. 2006.

Como se faz um texto: a construção da dissertação argumentativa. Catanduva: Rêspel, . Leitura, texto e hipertexto. In: MARCUSCHI, L. A.; XAVIER, A. C. dos S. (org.). Hipertexto e gêneros digitais: novas formas de construção de sentido. Rio de Janeiro: Lucerna, 2004. 